\title{
ENTREVISTA COM O PROFESSOR FLAVIO GARCÍA ACERCA DA LITERATURA INSÓLITA EM LÍNGUA PORTUGUESA
}

Por Bruno Anselmi Matangrano ${ }^{1}$

Doutor em letras, Flavio García é Professor Associado da UERJ, atuando na Graduação em Letras, bem como no Programa de Pós-Graduação em Letras - Mestrados em Literatura Portuguesa e em Teoria da Literatura e Literatura Comparada e Doutorado em Literatura Comparada. Coordena o SePEL.UERJ (Seminário Permanente de Estudos Literários da UERJ), cocoordena as Publicações Dialogarts e subcoordena o LABSEM (Laboratório Multidisciplinar de Semiótica). É líder do Grupo de Pesquisa Nós_do_Insólito: vertentes da ficção, da teoria e da crítica e participa do Grupo de Pesquisa Vertentes do Fantástico na literatura. Foi eleito para coordenar (2011-2016) o Grupo de Trabalho ANPOLL Vertentes do Insólito Ficcional, desde sua criação em julho de 2011, sendo reconduzido para o biênio que se encerra em 2016. Coorganizou as obras O insólito e seu duplo (EdUERJ, 2009), Vertentes teóricas e ficcionais do insólito (Caetés, 2012), As arquiteturas do medo e o insólito ficcional (Caetés, 2013) e Murilo Rubião - 20 anos depois de sua morte (EdUERJ, 2013). É autor de Discursos Fantásticos de Mia Couto (Dialogarts, 2013). Tem coordenado, ano a ano, eventos regionais, nacionais e internacionais acerca das Vertentes do Insólito Ficcional.

Bruno Anselmi Matangrano - Professor Flavio, para começar, o senhor poderia nos explicar o que entende por Insólito e porque preferiu dedicar seu grupo, evento e livros a esse "novo gênero" e não às categorias que vinham sendo estudadas até então como o Fantástico, o Maravilhoso, o Sobrenatural?

Flavio García - Na verdade, essas categorias, para muitos tratadas como gêneros, como o faz, por exemplo, Todorov em seu paradigmático Introdução à literatura fantástica, concluído ainda em 1969 e publicado em 1970, vinham e vêm sendo estudadas, junto a tantas outras, destacando-se as vertentes do Estranho e dos "Realismos" adjetivados de Maravilhoso, Fantástico etc., sem que se verifiquem distinções indiscutíveis entre elas. Isso

\footnotetext{
${ }^{1}$ Bruno Anselmi Matangrano é bacharel em Letras (português-francês), mestre e doutorando em Literatura Portuguesa, pela Faculdade de Filosofia, Letras e Ciências Humanas (FFLCH), da Universidade de São Paulo (USP). Tem sua pesquisa apoiada pelo CNPq.
} 
demonstra que a crítica não encontrou, e parece que não vai encontrar - Que bom! -, aparato teórico que dê conta desse universo difuso de manifestações ficcionais, que, no entanto, acabaram sendo aproximadas ao longo dos tempos. Fica a pergunta: se não são uma coisa única - e não são! -, por que se verifica, muito a miúde, alusão à vasta terminologia, às vezes em um mesmo estudo, para se referir às facetas desse tipo de literatura? $\mathrm{Na}$ resposta a essa pergunta que formulei, reside a resposta à parte da pergunta que me faz. O que aproxima essa diversidade da narrativa ficcional é a presença, nela, de um traço que a distingue de outras tantas diversidades, fazendo-a um conjunto próprio: em todas essas vertentes se manifesta o insólito. (Aliás, antes de optar pelo termo-conceito, recorri a diferentes estudos que vinculassem obras a alguma dessas variantes; reuni apresentações de livros, prefácios, orelhas, contra-capas de volumes em que se publicasse algo disso que estão chamando, na questão que me propõem, de categorias; pesquisei resenhas de jornal. Em tudo havia um termo comum: "insólito". Ora, vinha como substantivo, ora como adjetivo, mas sempre se referindo a aspectos próprios da ficção. $\mathrm{O}$ que, então, pode ser o traço distintivo desse conjunto difuso de obras literárias que se reúnem sob a égide do insólito ficcional? O semiólogo boliviano Renato Prada Oropeza, falecido em 2011, oferece, em um breve artigo publicado na Revista Semiosis (II, México, núm. 3, 2006: 53-76), excelente contribuição para que se defina o insólito. Tratar-se-ia da manifestação, em uma ou mais categorias básicas da narrativa - personagens, tempo e espaço - ou na ação narrada - sua natureza -, de alguma incoerência, incongruência, fratura de "representação" - no sentido mais primário da mimesis - referencial da realidade vivida e experienciada pelos seres de carne e osso em seu real quotidiano, como por exemplo, mimetiza a verossimilhança real-naturalista. Nesse sentido, pode-se dizer que existem, no mínimo, dois sistemas narrativo-literários: um real-naturalista, comprometido com a representação referencial da realidade extratextual; outro insólito - "não realnaturalista" -, que prima pela ruptura com a representação coerente, congruente, verossímil da realidade extratextual.

B. A. M. - Quem pela primeira vez estabeleceu este conceito?

F. $\boldsymbol{G}$. - Não saberia dizer com certeza e precisão. Descobri, recentemente, que, na Espanha, há grupos de estudo dedicados à narrativa insólita. De 5 a 7 de novembro deste ano de 2014, acontecerá, na Universidad de León, o Congreso Internacional Figuraciones de lo Insólito en las Literaturas Española e Hispanoamericana (Siglos XIX-XXI). Muito dispersa e 
discretamente, Antonio Candido empregou o termo, associado a outro de universo semântico próximo, para se referir à obra de Murilo Rubião, afirmando que, com o livro de contos O ex-mágico (1947), o escritor mineiro teria inaugurado, no Brasil, a ficção do insólito absurdo (“A nova narrativa”. In: Educação pela noite e outros ensaios. São Paulo: Ática 1987. p.208).

B. $\boldsymbol{A} . \boldsymbol{M}$. - O senhor acha que ainda há preconceito com quem pesquisa literatura Fantástica, ou Insólita? Se sim, acha que esse preconceito é maior no Brasil? E em Portugal?

F. $\boldsymbol{G}$. - Sempre houve e até hoje persiste o preconceito em relação à literatura nãorealista, que vem, em sua maioria, de parte da crítica "esquerdoíde" e míope. Pode ser anacrônico, mas ainda estamos em uma época em que se defende o compromisso da arte com valores tais ou quais para além dos valores da própria arte - não perco de vista os problemas da discussão acerca da "arte pela arte", mas arte é arte, e pronto, e literatura é arte. É lugar comum, por exemplo, ver os estudiosos das literaturas africanas repudiando qualquer crítica que se debruce sobre as vertentes do fantástico - ou do insólito, nesse caso, tanto faz. Para esses, por um lado, tudo que ali parece insólito, faz parte do sólito pretensamente real - e nisso perdem de vista a construção narrativa, os protocolos da ficção etc. -, por outro, a literatura de África fala de questões duras, que precisariam ser vistas sob um prisma realista. Assim, soa estranho aceitarem quando se leem as obras africanas com suporte em teorias que valorizam a história - no sentido estruturalista do termo - e não o enredo, iluminando as questões centrais do pós-colonialismo - a partir do eixo político, em sentido lato -, independentemente de essas teorias serem de origem ocidental, europeia ou americana, mas repudiam os estudos que ou se atêm à estrutura focalizam o enredo -, ou não têm por motivo - termo aqui emprego como o fizeram os formalistas - as questões coloniais ou pós-coloniais - está-se diante de outro problema quando se emprega esse termo: pós-colonial. Todavia, não se pode atribuir o preconceito apenas a essa questão - comum a várias escolas da crítica, em diferentes partes do mundo , mas há, também, o aspecto generalizante de repúdio à literatura de passa-tempo - escolhi o termo para fugir (sempre que posso fujo) de nomenclaturas problemáticas, como "literatura menor" ou congêneres -, que englobaria as vertentes do fantástico e algumas manifestações rotuladas por David Roas de pseudofantásticas, como a ficção científica, os romances policial e de mistério etc. ("Los pseudofantásticos y sus variantes”. In: Trás los 
límites de lo real: una definición de lo fantástico. Madrid: Páginas de Espuma, 2011. pp. 62 66.). O que eu disse reflete uma tensão relativa à crítica acadêmica, que vem sofrendo modificações drásticas e profundas, pois, no mundo todo - e, aqui no Brasil, estamos em compasso harmônico com o restante do mundo -, os programas de pós-graduação, os grupos de pesquisa, as publicações científicas etc. têm valorizado a pesquisa dessas variantes literárias que ousamos reunir sob a nomenclatura de insólito ficcional. Talvez o cinema seja o grande responsável por isso... Já há uma quantidade bem relevante de estudos que se atêm ao tema, como muitos títulos dedicados à crítica do fantástico, que vêm absorvendo a discussão, mas isso já dá para outra entrevista, bem mais complexa e ampla. O mesmo está se dando em Portugal, onde, de 19 a 21 de novembro deste ano de 2014, acontecerá, na Faculdade de Letras da Universidade de Lisboa, o Colóquio Internacional de Fiç̧ão Científica e Fantasia - Mensageiros das Estrelas - Episódio III, que está em sua terceira edição. (A propósito do preconceito reinante em Portugal desde o Século XIX, pode-se ler meu capítulo sobre "Um insólito e duplo Teófilo Braga" [In: O insólito e seu duplo. Rio de Janeiro: EdUERJ, 2009. pp. 141-155.], em que aponto a incoerência de um escritor que se filia à escola realista, lança farpas à literatura fantástica da época, mas cujo primeiro e único volume de literatura produzida pelo próprio punho intitulara-se Contos phantásticos).

B.A.M. - Normalmente, os países de língua portuguesa não são os mais conhecidos por sua produção em torno dos gêneros do Insólito. O senhor concorda com isso ou acha que muito da produção insólita de língua portuguesa foi negligenciada pela historiografia literária?

F. G. - Vou driblar a sua pergunta com uma questão mais genérica. Quando se fala em grande dramaturgia ocidental, vêm à mente, muito depressa, nomes como os do inglês William Shakespeare, do francês Molière, do alemão Bertolt Brecht, do italiano Luigi Pirandello... Alguém, que não seja um especialista, se lembra do nome de Gil Vicente, cuja obra desponta em 1502 e tem visibilidade até 1536? Ele não teria sido um precursor de alguns desses outros, em especial de Shakespeare e Molière? Sua crítica de fundo político em sentido mais amplo - não representaria um antecedente do teatro brechtiniano? Mas por que não se lembra de Mestre Gil? Porque a língua em que escreveu era a portuguesa. Essa explicação dá conta do aspecto internacional que a pergunta engloba, mas, sem dúvida, sob o ponto de vista interno, a historiografia literária nacional tem sua grande parcela de culpa. E de onde vem essa culpa? De algo que já disse antes: da incapacidade da 
crítica de dar conta da abordagem dessas vertentes literárias. Qual a razão de a crítica ser incapaz? Da falta de instrumentais teóricos mais aceitos pelo senso comum dos críticos, influenciados que estão pela sobrepujança do sistema narrativo-literário real-naturalista, cujo apogeu se deu exatamente com o avanço da imprensa e a difusão da obra literária. Esse cenário vem se modificando muito rapidamente.

B. $\boldsymbol{A}$. M. - Por outro lado, nos últimos tempos o número de publicações voltadas a essas temáticas cresceu muito. O senhor acompanha o crescimento do gênero no Brasil e no mundo? O que diz da atual produção da Literatura Insólita de Língua Portuguesa? Há algum nome que considere promissor?

F. G. - Cresce tanto o número de publicações ficcionais, quanto teóricas ou críticas, seja no Brasil ou no exterior. Isso é muito bom. A teoria e a crítica, venho lendo-as mais rapidamente, por imposição de ofício - docência, orientação, pesquisa, publicações. A ficção, leio-a mais devagar, mesmo porque há um hiato entre o que já deveria ter lido e o que de fato li, pois a formação anterior não me proporcionou essas leituras. Assim, sempre descubro uma narrativa de um autor consagrado que não li por não saber antes de sua existência, bem como também descubro autores novos para mim que têm obras vinculáveis ao insólito. Em 2011, Maria Cristina Batalha publicou O fantástico brasileiro: contos esquecidos (Rio de Janeiro: Caetés), dando uma grande contribuição à divulgação de autores e obras nacionais. Bráulio Tavares é outro que tem prestado excelentes serviços à propagação da literatura fantástica no país, publicando antologias com obras de autores estrangeiros e nacionais, além de, ele mesmo, despontar como ficcionista. Flávio Carneiro professor universitário, pesquisador, crítico e ficcionista - completou, recentemente, sua trilogia, em que visita o fantástico, com $A$ confissão (Rio de Janeiro: Rocco, 2006), a ficção científica, com $A$ ilha (Rio de Janeiro: Rocco, 2011) e o romance policial, com O livro roubado (Rio de Janeiro: Rocco, 2013). A proximidade da produção inibe o distanciamento crítico, logo, não me sinto à vontade para falar em nome promissor, mas temos o próprio Flávio Carneiro, o André Vianco, o Roberto Causo, não limitando a compreensão do fantástico à visão restritiva de Todorov, mas pensando o insólito como macro-categoria aglutinadora. 
B. A. M. - Se possível, gostaríamos que contasse um pouco do histórico do Grupo Nós do Insólito e do congresso Vertentes do Insólito Ficcional. Além disso, se possível, gostaríamos de saber quais são as perspectivas futuras do grupo e do evento.

F. G. - Será inevitável partir de mim mesmo, como centro desse percurso. Em 1994, após haver passado para o doutorado em Letras na PUC-Rio, viajei para fazer um curso de verão, em julho, na Universidade de Compostela, na Espanha. Fui com a cabeça cheia de medievalismo e paixão por Mestre Gil. Ao final de minha primeira aula, depois de haver lido um apaixonante conto de Manuel Rivas, dirigi-me à livraria ao lado do Instituto da Língua galega, para comprar o livro do Manolo, e a vendedora - uma senhora estranha, que pintava gatos ao fundo da lojinha - negou-se a vender qualquer coisa desse escritor se eu não comprasse algum livro de Xosé Luís Méndez Ferrín, que, segundo ela, era o grande escritor galego daquela atualidade. Sem questionar, comprei Percival e outras historias. Li sem parar, toda a tarde. Era excelente, invadia o mundo feérico da Idade Média celta, bretã... Passados vinte e sete dias, voltei para o Brasil com todos os livros de contos do Méndez Ferrín na bagagem, devidamente lidos e anotados. Tinha um autor para a tese, mas meu curso era em literatura portuguesa, e ficava faltando outro. Consultei, por carta, muitos professores portugueses, e David Mourão me respondeu, sugerindo que lesse os contos de Mário de Carvalho. Algumas narrativas pareceram-me chatas, outras encantadoras - Casos do Beco das Sardinheiras é uma dessas -, e acabei encontrando o par a formar com Méndez Ferrín. E o que aproximava os dois, mais especificamente no que se referia às narrativas que me encantavam? Aquilo que depois fui chamar de insólito. Em 1999 defendi a tese O Realismo Maravilhoso na Ibéria Atlântica - a narrativa curta de Mário de Carvalho e Méndez Ferrín. Em 2003, já como professor da UERJ, fui convidado pela Professora Maria do Amparo Tavares Maleval, que tivera sido minha orientadora de mestrado na UFF, a integrar a equipe de um projeto de cooperação interuniversitária UERJ - Universidade da Coruña, coordenado por ela. Precisava de um projeto de pesquisa que comparasse algo das literaturas brasileira e galega. Daí vieram Méndez Ferrín e Murilo Rubião. O embrião do "Nós do Insólito" havia sido germinado. No ano seguinte, para orientar Iniciação Científica, propus exatamente um projeto de comparação entre esses autores. Muito rapidamente, fomentado por meus bolsistas, em especial por Angélica Batista, que, mais tarde, viria a ser minha primeira mestranda orientada - ou desorientada, não sei -, o grupo crescia, tendo chegado a contar com treze bolsistas, entre os financiados pela UERJ, pela 
FAPERJ, pelo CNPq e os voluntários. Os encontros tornaram-se cursos livres de extensão, abertos a interessados. Assim, em janeiro de 2007, após um curso iniciático sobre os mecanismos de construção narrativa, realizamos o I Painel Reflexões sobre o insólito na narrativa ficcional. E de onde teria vindo a eleição do termo insólito nesse momento? Angélica, sempre arguta, dizia que sobrenatural, extraordinário, estranho etc. não eram a mesma coisa, ainda que reunidos naqueles estudos, faltando algo para designar a unidade dessa diferença. Lendo minha tese, ela disse que, várias vezes, eu empregava o termo insólito, e ela achava que dava conta do que era essa unidade na diferença. Foi então que fiz a primeira pesquisa da ocorrência do termo na tradição crítica - ensaios, resenhas, apresentações, prefácios, orelhas, contra-capas etc. Angélica é meio mãe do termo-conceito fixado por mim. A partir daí o evento foi crescendo: novos cursos, novos painéis, mais atividades. Em 2009, Karin Volobuef organiza na Unesp, campus Araraquara, o I Colóquio Vertentes do Fantástico na Literatura, e, por sugestão de Maria Cristina Batalha, eu me inscrevo no evento, levo mestrandos sob minha orientação, orientação de Flávio Carneiro e da própria Maria Cristina, com a missão de propor, à Karin, a criação de um Grupo de Trabalho na ANPOLL (Associação Nacional de Programas de Pós-Graduação e Pesquisa em Letras e Linguística). Eu e Karin iniciamos as discussões, que duram até 2011, quando nossa proposta foi apresentada à ANPOLL, sob a Designação de GT Vertentes do Insólito Ficcional. A escolha do termo insólito respondeu à fuga da restrição ao fantástico, para poder agrupar uma diversidade que já convivia harmoniosamente, e do ficcional, à assunção de que as manifestações do insólito não se limitam à ficção literária, mas a variadas narrativas ficcionais, como a fílmica, por exemplo. Aprovada a proposta pela ANPOLL, o Grupo foi instalado em julho de 2011, durante o Congresso Internacional da ABRALIC (Associação Brasileira de Literatura Comparada), em Curitiba. Eu e Karin fomos eleitos para a coordenação e a vice-coordenação, respectivamente. No ato de instalação do Grupo, decidimos que o evento do Rio de Janeiro teria uma versão internacional a cada dois anos, nascendo assim o Congresso Internacional Vertentes do Insólito Ficcional, intercalado com o evento da Unesp, que se manteria acontecendo circularmente nos campi de Araraquara (2009), São José do Rio Preto (2011) e Assis (2013), também a cada dois anos. Hoje, o GT ANPOLL tem permitido e propiciado integração nacional - e internacional - em rede de pesquisadores, de centros de estudos, de núcleos de pesquisa etc., prenunciando o fortalecimento das pesquisas em torno do insólito. O congresso internacional de 2016 deve ser produto de convênio entre a UERJ e a 
Universidade de Coimbra, reunindo dois grandes eventos, o Vertentes do Insólito Ficcional, promovido pelo SePEL, e o Figuras da Ficção, promovido pelo Centro de Literatura Portuguesa. A princípio, para fugir do tumulto dos Jogos Olímpicos no Rio de Janeiro, estamos pensando em realizar o evento entre setembro e outubro, tendo por tema central "Figurações do (In)Sólito". Enfim, as publicações vêm se multiplicando, novos grupos de pesquisa certificados junto ao Diretório de Grupos do CNPq vêm surgindo, mais e mais dissertações e teses vêm sendo defendidas e o insólito vêm se tornando mais sólito a cada dia. 